\title{
Relaciones comerciales entre la Corona de Aragón y Algeciras a mediados del siglo XIV. Algunos datos desde las fuentes documentales y el registro arqueológico
}

\author{
Antonio ToRREMOCHA Silva *
}

\begin{abstract}
RESUMEN
En este trabajo se analizan algunos testimonios documentaies y arqueológicos en relación con la colonia de mercaderes catalano-aragoneses asentada en Algeciras y los intercambios comerciales que existieron entre esta ciudad y territorios de la Corona de Aragón desde 1344 hasta 1369. La constatación del establecimiento en la ciudad de un Consulado de los Catalanes después de la conquista castellana $y$, sobre todo, la reciente recuperación de cerámica gótico-mudéjar valenciana en diversas intervenciones arqueológicas, permiten acrecentar el conocimiento que se tenía hasta el momento sobre las relaciones de tipo comercial que los catalanoaragoneses mantuvieron con la región del Estrecho en la segunda mitad del siglo XIV.
\end{abstract}

\section{ABSTRACT}

This article analyses some archeological and documental testimonies in relation with the group of catalonian-aragoneses merchants established in the city of Algeciras, and the trade between this city and some territories of the Crown of Aragón, from the year 1344 to 1369 . The verification of the settlement in the city of a catalonian Consulate, after the conquer of the city by Castile, and over all, the recent findings of valencians gothicmudejar ceramics in different archeologic sites, allow to increase the knowledge about the trade of the catalonian-aragoneses in the Strait during the second half of the XIV century.

* UNED. Centro Asociado de Algeciras. 


\begin{abstract}
PALABRAS CLAVES
Algeciras. Corona de Aragón.

Relaciones comerciales. Consulado

Catalán. Cerámica gótico-mudéjar

valenciana.
\end{abstract}

«Mi emocionado recuerdo al profesor y hombre bueno, Antonio Antelo.»

\title{
1. ARAGÓN EN EL ESTRECHO DE GIBRALTAR
}

Desde mediados del siglo XIII Castilla controlaba los territorios de la Andalucía Occidental. Ciudades tan emblemáticas para el Islam hispano, como Córdoba, Jaén y Sevilla eran conquistadas por el reino castellano en 1236,1246 y 1248 , respectivamente, mientras que en la zona oriental de la actual Andalucía se constituia el epígono reino musulmán de Granada encastillado entre las sierras subbéticas y penibética. Aragón, tras los acuerdos de Almizra (1244) había dado fin a su empresa conquistadora en su zona de influencia, permaneciendo al margen de la lucha por el dominio de lo que quedaba de al-Andalus. Pero el acercamiento de la frontera castellana a la región del Estrecho, que fue el detonante de la reacción normagrebí que puso en peligro los territorios ganados por los cristianos al sur de Sieira Morena, hicieron comprender a los reyes castellanos la imperante necesidad de controlar el Estrecho de Gibraltar para impedir la irrupción de nuevos contingentes norteafricanos y poder consolidar sus posesiones en la banda atlántica de la actual provincia de Cádiz. Como acertadamente apunta Angel Canellas «no bastaba con ocupar el reino granadino; se necesitaba garantizar la Península contra posibles reacciones e invasiones norteafricanas" '. Para aquella nueva etapa de lucha contra el Islam, en la que el dominio del mar se presentaba como un factor decisivo, la colaboración de la Corona de Aragón se hacía imprescindible. Por ello, a partir del reinado de Sancho IV se abrieron nuevas vías de colaboración entre Castilla y Aragón comprometiéndose este reino a participar en la Batalla del Estrecho a cambio de la cesión de áreas de influencia en Marruecos y la posibilidad de nuevas anexiones en territorio granadino ?

CANElLAS, A., «Aragón y la empresa del Estrecho en el siglo XIV. Nuevos documentos del Archivo Municipal de Zaragoza", en Estudios de Edad Media de la Corona de Aragón, Sección de Zaragoza, CSIC, Escuela de Estudios Medievales, vol. II, Zaragoza, 1946, p. 10.

2 Sancho IV acordará con Jaime II la cesión a Aragón de una zona de influencia en Marruecos (1291) y Fernando IV ofrecerá al rey aragonés, en el Tratado de Alcalá de 1309, el reino de Almería, a cambio de su participación en la Batalla del Estrecho. 
Desde el año 1309 los aragoneses optarán por intervenir de una manera activa en la zona del Estrecho, bien directamente (ataques a Ceuta y Almería), bien indirectamente mediante la cesión de su escuadra a los castellanos. La flota aragonesa y las tropas de tierra meriníes conquistaron Ceuta a los nazaríes en $1309^{3}$, mientras Jaime II ponía cerco a Almería y Fernando IV sitiaba Algeciras. Sin embargo, ambos cercos fracasarian. Un largo período de treguas y alianzas, con algunos esporádicos episodios bélicos (reconquista de Gibraltar por los meriníes en 1333), alargarán el problema del Estrecho hasta el año 1338, cuando, ante el temor de un gran desembarco africano, se refuercen las alianzas entre Pedro IV y Alfonso XI para incrementar la defensa del Estrecho ${ }^{4}$. A partir de ese momento Aragón desempeñará un papel destacado en la pugna por el dominio del mar hasta la conclusión del conflicto tras la victoria del Salado (1340) y la rendición de Algeciras (1344). El control del Estrecho se había decantado, finalmente, del lado cristiano. Sin embargo, Castilla no pudo sacar provecho de la nueva situación en la zona. Muerto Alfonso XI frente a Gibraltar en 1350 , al reino castellano le esperaba una larga y perniciosa guerra dinástica que frenó su impulso conquistador hasta bien entrado el siglo XV. Aragón, en cambio, vería reforzada su presencia en la región abriéndosele nuevos mercados en competencia con los genoveses y consolidando sus relaciones comerciales con los emiratos de ambas orillas ${ }^{5}$ (Fig. 1).

3 Jaime II y el emir meriní Abu-I-Rabi acordaron la conquista de Ceuta y las condiciones de la participación aragonesa mediante un Tratado de Paz y Alianza acordado en el mes de mayo de 1309 entre ambos reyes. Véase su contenido en: Capmany y de MontPalau, A., Antiguos tratados de paces y alianzas entre algunos reyes de Aragón y diferentes príncipes infieles de Asia y África desde el siglo XIII hasta el XV, copiados con orden de $S$. $M$. de los originales registros del Real $y$ General Archivo de la Corona de Aragón, establecido en la ciudad de Barcelona, por..., vertidos fiel $y$ literalmente del antiguo idioma lemosino al castellano y exomados con varias notas históricas, geográficas y políticas, Madrid, 1786, pp. 5 a 17. Un análisis de los acontecimientos desde las fuentes árabes y cristianas, en Manzano Rodríguez, M. A., La intervención de los benimerines en la Península Ibérica, CSIC, Madrid, 1992, pp. 176 a 187.

4 Aragón tenía fundadas sospechas de que un desembarco masivo merini acabaría por llevar la guerra a sus propios territorios. Esta sospecha, además de otros motivos de naturaleza económica o ideológica, debió impulsar al rey aragonés a proporcionar ayuda militar a Castilla. Giménez Soler aporta algunos documentos reveladores sobre el peligro que amenazaba a Aragón desde Berbería (GIMÉNEZ SOLER, A., «La Corona de Aragón y Granada», Boletín de la Real Academia de Buenas Letras, T. IV, Barcelona, 1907-08, pp. 262 a 265).

Véase: Alarcón y Santos, M.A. y García LinARES, R., Los documentos árabes diplomáticos del Archivo de la Corona de Aragón, Escuela de Estudios Árabes de Madrid y Granada, Madrid, 1940, Cartas $n .{ }^{\circ} 56,68,69,70,71,72,73,74,75,76,96,100,101,102,104,106$, y 109. No podemos obviar, en estas relaciones con los emiratos musulmanes de Granada y el Norte de África, la actividad corsaria de la que nos da buena cuenta la correspondencia diplomática de la época analizada por Manuel Sánchez Martínez para los años 1344 y 1345 (SÁnchez Martínez, M., «Comercio nazarí y piratería catalano-aragonesa (1344-1345)», en Actas del Coloquio Relaciones de la Península Ibérica con el Magreb (siglos XII-XVI), CSIC, Instituto Hispano-Árabe de Cultura, 


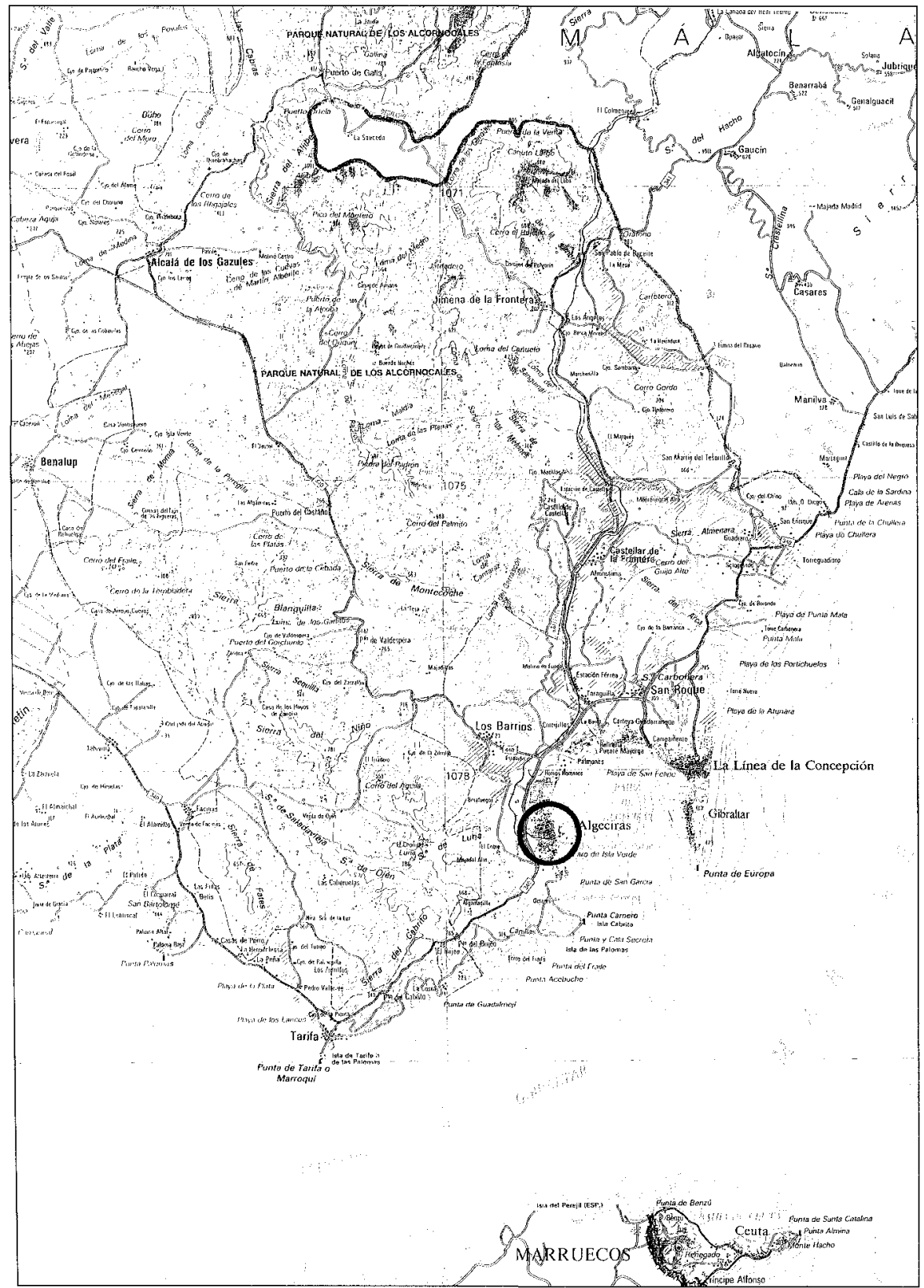

Fig. 1. Situación de la ciudad de Algeciras en relación con el Estrecho de Gibraltar. 
Al margen de los motivos de autodefensa que podía tener el rey de Aragón para intensificar, desde 1338, la participación de su reino con navíos y vituallas en la pugna por el control del Estrecho que mantenía en solitario Castilla, se pueden aducir otras motivaciones a las que no eran ajenas las potencias cristianas de la época cuando intervenían en los conflictos contra los musulmanes. Las razones de tipo político (incrementar el prestigio de la monarquía y del reino, lograr la anexión de nuevos territorios, etc...) y económicos (apertura de nuevos mercados, contrapartidas comerciales con Castilla, etc...), no debieron quedar al margen de las causas que llevaron a Pedro IV a prestar una ayuda, casi continua, al rey de Castilla hasta el año 1344. Pero no debemos ignorar las motivaciones de naturaleza espiritual (el ideal de Cruzada y la colaboración en la «guerra justa") que aparece recogida, expresamente o de manera subliminal, en algunas de las cartas que el rey de Aragón remitió a Alfonso XI, a Don Juan Manuel y a Mateo Mercer entre 1338 y $1344^{6}$.

\section{PARTICIPACIÓN DE ARAGÓN EN LA CAMPAÑA DE ALGECIRAS (1342-1344)}

El cerco de Algeciras representó, con la decisiva victoria del Salado, el hecho de armas más destacado de cuantos se sucedieron en lo que se ha venido en denominar la Batalla del Estrecho. En torno a Algeciras y en los veintiún meses que duró el asedio se concentró una fuerza militar de carácter internacional comparable sólo a la reunida en la Batalla del Salado dos años antes ${ }^{7}$. Por tierra los ejércitos de Castilla (Infantes, nobles, tropas reales, milicias concejiles, mesnadas nobiliarias y cruzados extranjeros, apoyados por zapadores, alarifes, carpinteros, canteros y artilleros) y por mar las escuadras coaligadas de Castilla, Aragón y Génova, se enfrentaron a las fuerzas musulmanas nazaríes y meriníes en una empresa que se preveía decisiva para el resultado final de la contienda en la región.

\footnotetext{
Madrid, 1988, pp. 41 a 86). Veáse, también: MUTGÉ VIVES, J., «Algunas noticias sobre las relaciones entre la Corona de Catalano-Aragonesa y el reino de Túnez de 1345 a $1360 \%$, en Actas del Coloquio Relaciones de la Península lbérica con el Magreb (siglos XIII-XVI), CSIC, Instituto HispanoÁrabe de Cultura, Madrid, 1988, pp. 131 a 164).

6 Carta de Pedro IV a Don Juan Manuel (Archivo de la Corona de Aragón, Cancillería, Registro 1.114, fol. 12 v. ${ }^{\circ}$ ), Carta de Pedro IV al rey Alfonso XI fechada el 20 de octubre de 1343 (ACA, Cancillería, Registro 1378, fol. 134 r. $^{\circ}$ ), Carta de Pedro IV a Mateo Mercer fechada el 6 de abril de 1344 (ACA, Cancillería, Registro 1059, fol. 109 r. ${ }^{\circ}$ ), entre otras.

7 Sobre los diversos aspectos del cerco, véase: Torremocha Silva, A., Algeciras entre la Cristiandad y el Islam, Instituto de Estudios Campogibraltareños, Algeciras, 1994, pp. 121 a 241.
} 
Aragón participó decididamente en la campaña de Algeciras con el envío de diez galeras al mando de su almirante Pedro de Moncada desde el verano de $1341^{8}$, relevado durante los meses que se alargó el cerco por los vicealmirates Mateo Mercer y Jaime Escribá ${ }^{9}$. En la etapa final del asedio, Aragón tuvo en aguas de la Bahía de Algeciras un total de veinte galeras, que con las 56 galeras castellanas y genovesas y las 40 naves de Castilla representaban una considerable fuerza naval, no cabe duda que decisiva a la hora de lograr la rendición de los sitiados en el mes de marzo de 1344. A pesar de las dificultades (irregularidades en la recepción de las pagas para la marinería, guerra con el rey de Mallorca, intentos de abandono del cerco por parte de los almirantes aragoneses, etc.), la aportación naval de Aragón a la empresa algecireña fue constante, aunque no en la cuantía que hubiera deseado el rey de Castilla.

Por otra parte, Aragón prestó una inestimable ayuda a los castellanos en lo que se refiere al abastecimiento de la hueste y el apoyo logístico durante los meses que duró el cerco. La frecuente llegada de trigo y cebada desde Aragón o sus territorios Mediterráneos para el ejército sitiador está documentada en la correspondencia diplomática que mantuvieron el rey de Castilla y Don Juan Manuel con el rey Pedro IV ${ }^{10}$. Pero este aspecto de la colaboración de Aragón parece que tuvo alguna quiebra en los meses finales del cerco, pues en una carta remitida por Alfonso XI al rey aragonés el 20 de enero de 1344, aquél le comunica que, a pesar de existir autorización real para que los mercaderes de Aragón pudieran llevar viandas al real de Algeciras, «por la qual rason avemos avido grant acorro de viandas en este real...", le reitera la petición de que deje salir vituallas de su reino ya que tiene noticias de que hay mercaderes que tienen mercancías preparadas en Aragón y no se las dejan sacar ${ }^{11}$. En lo

8 Un año antes (primavera de 1340), el almirante de Aragón, Jofre Gilabert de Cruilles había encontrado la muerte al desembarcar cerca de Algeciras. La Crónica de Alfonso XI da la fecha de septiembre de 1339, aunque el suceso debió acontecer a principios de la primavera de 1340 (Crónica de Don Altonso el Onceno, BAE, Edit. Atlas, Madrid, 1953, p. 303).

9 ACA, Cancillería, Registro, $n .^{\circ} 1.117$, fol. $18 v^{\circ}$.

10 El 3 de abril de 1343 el rey de Aragón autoriza la saca de mil cahices de cebada desde Aragón con destino al ejército cristiano que sitiaba Algeciras (ACA Cancillería, Registro 1.059, f. 27. Publicado por Giménez Soler, A., Don Juan Manuel. Biografía y Estudio, Academia Española, Zaragoza, 1932, p. 641). En otra carta del rey de Aragón al de Castilla, fechada en 20 de octubre del mismo año, aquél le comunica que "Quanto al feyto de las viandas nos respondemos que nos escriviremos por nuestros rregnos a las ciudades e villas majorment a aquellas que son riba la mar que lieven viandas segunt han costumado al sitio de la villa Dalgezira porquel sitio se tiene poderosament e esforçada e se continuara con la ayuda de Dios entro que la dita villa sea presa" (ACA, Cancillería, Registro 1.378, f. 134).

11 ACA, Cartas Reales, N. ${ }^{\circ} 84$ (20 de enero de 1344), publicada en CODOIN del Archivo General de la Corona de Aragón, por Próspero Bofarull y Mascaró, Barcelona, 1850, Tomo VII, pp. 174-175. 
que respecta al apoyo logístico, de los pinares de Moya llegaba la madera que era necesaria para la edificación de casas en el real y para la construcción de maquinas de asedio y artilugios neurobalísticos ${ }^{12}$. Aunque el término de Moya se hallaba situado en la serranía de Cuenca, para el transporte de la madera se utilizaba el río Guadalaviar, cruzándose, por tanto, territorios del rey de Aragón, lo que obligaba a contar con su expresa autorización.

Del análisis de la Crónica castellana y de la documentación existente en el Archivo de la Corona de Aragón y el Archivo Municipal de Valencia, se infiere que la participación aragonesa en el cerco de Algeciras fue muy intensa y, en cierta manera, decisiva para el resultado final de la empresa, abarcando dicha participación no sólo la ayuda militar (flotilla de galeras y caballeros cruzados con sus mesnadas), sino también ayuda logística y avituallamiento de la tropa ${ }^{13}$. La implicación de los aragoneses en la campaña de Algeciras fue tan profunda y de tanto calado popular que la rendición de la ciudad en marzo de 1344 se consideró como un triunfo propio ${ }^{14}$. Al mismo tiempo, la ayuda prestada por este reino en la pugna por el control del Estrecho, sobre todo durante la campaña de Algeciras, le permitió participar con ventaja en los beneficios de la victoria a través del repartimiento de la Villa Nueva y de concesiones comerciales en la ciudad reciérı conquistada.

\section{ESTABLECIMIENTO DE ARAGONESES Y GENOVESES EN ALGECIRAS (1344-1369)}

Una vez concluido el cerco de la ciudad, el rey de Castilla procedió al repartimiento de los bienes inmuebles de ambas villas entre aquellos

12 Crónica de Don Alfonso el Onceno, op. cit., p. 348.

13 En el mes de noviembre de 1343 «mercaderes catalanes», abastecieron de «cebada et farina” el real castellano con navíos que llegaron desde Cerdeña (Crónica de Don Alfonso el Onceno, op. cit., p. 381).

14 En una carta fechada el 26 de marzo de 1344 - el mismo dia de la rendición de al-Binya o Villa Nueva - el vicealmirante de Aragón, Mateo Mercer, le comunicaba al rey de Aragón como «en hora de tercia los estendarts vostre e del Rey de Castiella entraren en la vila nova de Algesira e don Johan Manuel e el vezcomte de Cabrera e Anrich Enrriquez e lalmirant de Castiella e jo cascun ab certes companyas entram en la vila ab los dits estendarts..." (ACA, Registro 1.059, f. 109. Publicado por A. Giménez Soler, op. cit. -1932-, p. 642). En el Manual de Consell de la ciudad de Valencia se inserta la carta de Mateo Mercer con el añadido de que el rey de Castilla «ha ordenat que l'estandart del rey d'Arago e el seu entren per egual la i del altre en l'entrar de les dites viles, e totes aquelles honors que seran fetes al estandart del rey de Castella, seran fetes al del rey d'Arago" (Archivo Municipal de Valencia, Manual de Consell, A 4, f. 309 v. ${ }^{\circ}$. Recogido por 
que habian participado en la empresa ${ }^{15}$. La presencia de nobles, mesnaderos, marineros y mercaderes originarios del reino aragonés en el real cristiano de Algeciras, así como el esfuerzo militar y económico realizado por el rey Pedro IV, había sin duda situado en una posición privilegiada a Aragón en el momento de procederse al reparto de propiedades y de otorgar concesiones de tipo comercial. Algeciras se hallaba situada en una zona de gran valor estratégico y gozaba de una larga y reconocida tradición como puerto comercial y de enlace con el Norte de África, lo que la convertía en un enclave de notable interés para las potencias comerciales mediterráneas (Aragón y Génova) que habían participado en el cerco y conquista de la ciudad y que aspiraban a reforzar los intercambios que ya mantenían con la costa atlántica hispana y magrebí. En este orden de cosas, no cabe dudas que el Tratado de Algeciras, firmado el 25 de marzo de $1344^{16}$, posibilitó el establecimiento de una larga etapa de paz entre los reinos contendientes y la mejora de los niveles de intercambios existentes entre las potencias cristianas y las musulmanas en los entornos del Estrecho.

En el real castellano, durante los meses que duró el asedio, residieron mercaderes de Aragón y de Génova que en momentos de apuro del rey castellano llegaron hacer prestamos a Alfonso XI ${ }^{17}$. La presencia de Egidiol Bocanegra como almirante de la escuadra castellana y beneficiado también con propiedades en el repartimiento de la ciudad, sería un buen aval para los mercaderes genoveses que esperaban instalarse en Algeciras ${ }^{18}$.

Se dispone de alguna documentación dispersa en la que se hace referencia a donaciones de casas, huertas, baños o mezquitas a particulares o

Dualde Serrano, M., Solidaridad espiritual de Valencia con las victorias cristianas del salado y Algeciras, Instituto Valenciano de Estudios Históricos, Diputación Provincial de Valencia, Valencia, 1950, p. 43).

i5 No se ha conservado el Libro de Repartimiento, aunque existen referencias documentales de algunas donaciones de casas, huertas y otra propiedades, así como de repobladores que acudieron a residir a Algeciras en los años siguientes a la conquista. (Véase: TorRemocha SiLVA, A., op. cit. -1994-, pp. 269 y ss).

16 Un traslado notarial, incompleto, se conserva en el Archivo de la Corona de Aragón (ACA, Cartas Reales, N. 84 , en CODOIN, op. cit., doc. n. 51 y TORREMOCHA Silva, A., op. cit. - 1994-, pp. 355 y ss.).

17 «Pero cató emprestado de mercaderes catalanes et de ginoeses que estaba y (en el real de Algeciras)... „ (Crónica de Don Affonso el Onceno, op. cit., p. 383).

is Don Egidiol había sido nombrado Almirante de Castilla en 1341. Con este nombramiento lograba Alfonso XI ganar un experto marino para dirigir la escuadra en la lucha que se avecinaba, asegurar la ayuda naval de Génova y acercar a su causa a la influyente y rica colonia de genoveses asentada en Sevilla. 
corporaciones en los meses que siguieron a la rendición de la ciudad ${ }^{19}$. Lo que si está suficientemente constatada es la extrema dificultad que encontró Castilla a la hora de acometer la repoblación del término y asentar a nuevos pobladores en la zona ${ }^{20}$. La situación geográfica de la ciudad recién incorporada (alejamiento de los núcleos urbanos castellanos más importantes Jerez y Sevilla-, cercanía de bases marítimas musulmanas - Ceuta y Gibraltar-, dificultad para guarnicionar y defender un recinto murado de cinco kilómetros de perímetro) (Fig. 2), todo ello en el marco de una situación de crisis demográfica, política y económica generalizada, impidieron la reocupación de la ciudad por suficientes pobladores, ocasionando una crónica situación de indefensión que posibilitó que los nazaríes, con la ayuda naval meriní, recuperaran la plaza en el año $1969^{21}$. Pero en los veinticinco años de dominio castellano - sobre todo entre 1344 y 1349 - el esfuerzo por consolidar la posición de Algeciras, fue muy intenso. El proceso de repoblación, dirigido por la Corona y secundado por algunas instituciones y particulares, tenía como principal objetivo el convertir Algeciras en la gran fortaleza del Estrecho y en el punto de arranque de la definitiva campaña de conquista del Reino de Granada. $Y$ en ese esfuerzo repoblador tuvieron un protagonismo destacado los mercaderes del Reino de Aragón y de Génova.

19 Barrantes Maldonado refiere que, antes de abandonar Algeciras, "Alfonso XI mandó partir las casas, tierras y heredades por los que avian de quedar á poblar á Algezira" (BARRANTES Maldonado, P., Ilustraciones de la Casa de Niebla, Colección Fuentes para la Historia de Cádiz y su Provincia, N. ${ }^{\circ}$ 3, Universidad de Cádiz, 1998, p. 201). Por un privilegio otorgado en Sevilla el 25 de mayo de 1344, el rey de Castilla hizo donación a Don Egidiol Bocanegra de «unas cassas con su huerta en la villa de Algeçira a las cuales cassas dizen el alcaçar de Manifle» (Real Academia de la Historia, Colección Salazar, M. 114. Publicado por A. TorREMOCHA SILvA, op. cit. -1994-, pp. 362 a 365). En el mismo documento se hace mención a «los nuestros baños», de lo que se deduce que el rey de Castilla se había reservado para él la propiedad de uno de los baños existentes en la ciudad. Doña Leonor de Guzmán y sus hijos recibieron también propiedades en Algeciras. En 1349 ésta donó a su hijo Don Fabrique diversos bienes -molinos, casas, tiendas y huertas - que ella había recibido del rey cuando se hizo el repartimiento de la ciudad (Real Academia de la Historia, Colección Salazar, M. 6, fol. 21 v. , recogido en Bullarium Equestris Ordinis Sancti lacobi de Spanha, Madrid, 1719, p. 308). Igualmente recibieron casas en Algeciras el Obispo de Cádiz y los canónigos beneficiados de su iglesia.

20 Para atraer repobladores, a instancia del rey de Castilla se erigió una nueva diócesis con cabecera en Algeciras y Cádiz, se otorgó a la ciudad un ordenamiento regio, se concedieron exenciones y franquicias fiscales y comerciales (derecho de ancoraje, exención del pago de moneda forera y de la alcabala, etc.). Aunque todas estas medidas no lograron atraer pobladores suficientes ni asegurar el abastecimiento de una plaza fronteriza tan amenazada por tierra y mar como era Algeciras, sobre todo en unos años en que la crisis dinástica, las pugnas nobiliarias, la peste negra y la general crisis alimentaria que sufría Castilla estaban ocasionando el despoblamiento y la indefensión de fortalezas castellanas situadas incluso lejos de la inestable frontera del Estrecho (Véase: Torremocha Silva, A., op. cit. -1994-, pp. 266 a 272).

${ }_{21}$ Ibn JALDUN, Histoire des Berbères et des dynasties musulmanes de l'Afrique septentrionale, Trad. por el Baron de Slane, Nueva edición publicada bajo la dirección de P. Casanova, París, 1969, Tomo IV, p. 381 y Crónica de Don Enrique Segundo, BAE, Edic. Atlas, Madrid, 1953, Tomo LXVIII, p. 4. 


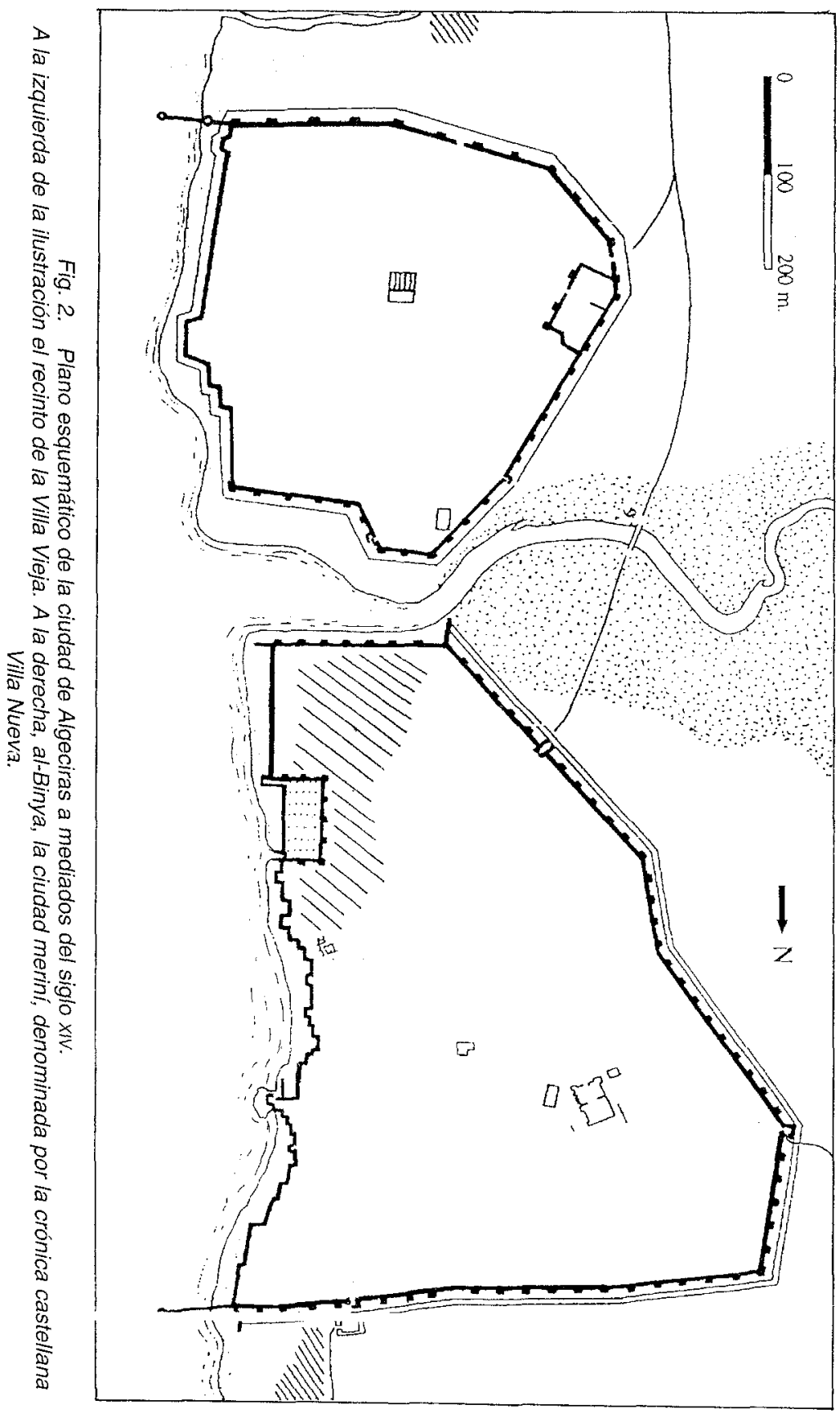




\subsection{El Consulado de los Catalanes}

Un personaje que iba a desempeñar un importante papel en el establecimiento de los catalano-aragoneses en Algeciras sería Don Juan, hijo del Infante Don Manuel, que había participado muy activamente en la campaña de Algeciras ${ }^{22}$ y mantenía excelentes relaciones con el Reino de Aragón. Estaba casado con Doña Constanza, Infanta de ese reino, y poseía extensas propiedades en Castilla no lejos de la frontera con Aragón ${ }^{23}$. Durante el cerco de la ciudad mantuvo correspondencia directa con el rey Pedro IV, al margen de la que existía entre los dos monarcas. Todo ello le daba gran ascendiente entre los caballeros de Aragón que se hallaban asentados en el real castellano. Del análisis de la documentación existente se puede deducir que en el repartimiento de la Villa Nueva, al-Binya o ciudad meriní, participaron muy activamente aragoneses y genoveses como pago a la ayuda prestada durante el cerco, mientras que la Villa Vieja, donde se hallaban los edificios más nobles (alcázar viejo y mezquita aljama) quedó en exclusiva para los repobladores castellanos. No obstante, en la Villa Nueva, la familia real castellana se reservaría algunas propiedades, entre ellas los baños que se localizaban junto al Alcázar de Manifle.

Dos testimonios documentales vienen a confirmar la presencia de mercaderes aragoneses y genoveses entre los repobladores de la ciudad. Por una parte la expresa mención, en uno de ellos, del Consulado Catalán de Algeciras, lo que revela la existencia de una colonia aragonesa en la ciudad, formada sobre todo por mercaderes catalanes, durante buena parte de los veinticinco años que estuvo Algeciras bajo dominio castellano (al menos hasta el año 1359). Por medio de una carta, fechada el 14 de marzo de 1356, el rey de Aragón comunicaba al cónsul de los catalanes en diversos puertos mediterráneos y atlánticos, entre ellos el de Algeciras, que antes de cumplido el plazo de dos meses todos los bajeles aragoneses que se hallaran en dichos lugares retornaran a puertos del rey de Aragón a causa de la guerra que mantenía con los genoveses ${ }^{24}$. Unos años más tarde, en

22 La Villa Nueva se rindió a Don Juan Manuel, el cual la recibió en nombre del rey de Castilla (Crónica de Don Alfonso el Onceno, op. cit., p. 389).

23 Tenía posesiones en Villena y Elche y era Adelantado de Murcia, lo que le hizo cuidar con esmero sus relaciones con la familia real aragonesa, llegando a concertar el matrimonio de su hijo Fernando con doña Juana, hija del Infante Ramón Berenguer y nieta de Jaime II (Para mayor abundancia sobre la vida y la obra de este personaje, véanse: GIMÉnEz SOLER, A., op. cit. y Moxó, Salvador de, «La sociedad política castellana en la época de Alfonso Xl», en Cuadernos de Historia, anexo de la revista Hispania, $n^{\circ} 6$, Madrid, 1975, pp. 213 a 219).

24 Entre otros, la carta está dirigida a los cónsules de los catalanes en Palermo, Mesina, Pisa, Catania, Trápani, Nápoles, Algeciras, Tenes, Bugía, Cartagena, Almería, Argel, Sevilla, 
1359, vuelve a mencionarse el consulado catalán algecireño en una carta enviada por Pedro IV a los cónsules de esta ciudad, de Cartagena y Sevilla instándoles a que volvieran a Aragón todos los catalanes que residieran en las citadas ciudades, a causa de la guerra abierta entre Aragón y Castilla ${ }^{25}$. Según José Hinojosa Montalvo, Algeciras y Tarifa son los puertos andaluces más frecuentados por las naves de comercio valencianas hasta la década de 1380, cuando dejan de mencionarse en las relaciones del Archivo de la Corona de Aragón y el Archivo del Reino de Valencia ${ }^{26}$.

Pero los catalanes tuvieron que competir en el área del Estrecho con los mercaderes genoveses, asentados en esta ciudad -donde el Almirante de Castilla, el genovés Don Egidiol Bocanegra, tenía propiedades-y en Sevilla, donde desde un siglo antes se hallaba establecida una influyente colonia italiana. Su participación en el cerco de Algeciras les había proporcionado una evidente ventaja a la hora de compartir los beneficios de la victoria. Está documentada la existencia de una calle de Génova en la Villa Nueva ${ }^{27}$, en los entornos del alcázar de Manifle, propiedad del Almirante de Castilla.

De lo expresado en este apartado se puede avanzar la hipótesis de que al-Binya, la ciudad meriní de Algeciras, denominada por las fuentes cristianas Villa Nueva, donde se localizaban las atarazanas y la zona artesanal,

Málaga, Bona, Alcudia, Mostaganem, Túnez y Ceuta (ACA, Registro 1.402, fol. 38 v. ${ }^{\circ}$. Véase el Apéndice Documental). El apoyo de Aragón a la causa Trastámara tuvo sus repercusiones en la actividad comercial. En 1356, Pedro I había confiscado los bienes de los mercaderes catalanes establecidos en Sevilla por no haber querido el almirante catalán, Francisco de Perelló, dejar en libertad unos navíos italianos que había capturado en aguas andaluzas. Según J. Lalinde las funciones de los consulados eran la protección de los intereses de los comerciantes, como colectividad y como individuos; favorecer el comercio a través del depósito de mercancías; facilitar el tránsito de los comerciantes, tanto en su alojamiento, como en su esparcimiento, y mediar y decidir en los litigios surgidos entre ellos (LALinde ABADÍA, J., La Corona de Aragón en el Mediterráneo Medieval (12291479), Instituto Fernando el Católico (CSIC), Zaragoza, 1279, p. 156).

25 ACA, Registro 1.403, fol. 128. Citado por Dufourq. Ch. E., «Les relations de la Péninsule Ibérique et de l'Afrique du Nord au XIV siècle», AEM, n. ${ }^{\circ} 7,1970-71$, p. 56

26 Hinojosa Montalvo, J., «Las relaciones comerciales entre Valencia y Andalucía durante la Baja Edad Media", en // Coloquio de Historia Medieval Andaluza, Sevilla 8/10 de abril de 1981 , Diputación Provincial de Sevilla, 1982, p. $25 i$.

27 En el privilegio de donación del Alcázar de Manifle a Don Egidiol Bocanegra se dice: «e damosbos las dichas cassas e guerta con todas las otras cassas que se contienen en la barrera que está a las espaldas de las dichas cassas que son en la calle que dizen de Genua..." (Real Academia de la Historia, Colección Salazar, M. 114. Publicado por A. Torremocha Silva, op. cit. -1994-, p. 363). El poseer calle propia era un derecho que podía conceder el rey de Castilla a una colonia extranjera por los servicios que ésta le habia prestado. El 25 de agosto de 1346, Alfonso XI concedió a los genoveses instalados en Sevilla el derecho a poseer una calle propia (González Gallego, l., "El Libro de los Privilegios de la nación genovesa», HID, n. ${ }^{\circ}$-1974-, pp. 275-358, Doc. n. ${ }^{\circ} 7$ ). 
se convirtió, tras la conquista castellana, en el foco comercial de la ciudad merced a la presencia de las colonias catalano-aragonesa y genovesa, en tanto que la medina andalusí, conocida como Villa Vieja, quedó reservada como espacio áulico y militar (alcázar), centro del poder religioso (mezquitacatedral de Santa María de la Palma) y de la administración del concejo municipal recién establecido ${ }^{28}$.

Por otra parte, la documentación consultada permite afirmar que la actividad comercial desarrollada desde 1344 entre la costa valenciana y catalana y la Bahía de Algeciras se vio perjudicada por el conflicto dinástico entre petristas y trastamaristas. El apoyo de Aragón a la causa trastámara debió provocar un descenso importante en el nivel de intercambios entre ambas zonas litorales, descenso que se acentuaría en 1359 cuando el rey de Aragón ordenó el retorno de todos los comerciantes catalanes establecidos en Sevilla y Algeciras a causa de la guerra con Castilla. La reconquista de la ciudad por Muhammad V de Granada en 1369 y la destrucción de la misma diez años más tarde, cerraron definitivamente el ciclo histórico de la Algeciras medieval poniendo fin a los intercambios comerciales que mantenía con la región valenciana, como bien ha constatado Hinojosa Montalvo ${ }^{29}$.

\section{APORTACIONES DESDE LA ARQUEOLOGIA: LA CERÁMICA GÓTICO-MUDÉJAR DE PATERNA-MANISES}

Hasta el año 1995, los trabajos de investigación sobre la Algeciras medieval se habían apoyado casi exclusivamente en el análisis de las fuentes escritas (documentos y crónicas árabes y cristianas) y de la bibliografía moderna y contemporánea que, con mayor o menor acierto, habían tratado este esquivo período de la historia de la ciudad del Estrecho. Sin embargo, a partir de esa fecha, en la que inauguró el Museo Municipal de Algeciras y se creó el Equipo de Investigación de dicho Museo del que forman parte arqueólogos, arabistas, documentalistas, restauradores e historiadores del arte, a las fuentes de carácter literario se han venido a añadir los abundantes testimonios que ha aportado el registro arqueológico merced a las treinta y seis intervenciones de urgencia y una sistemáticas que se han realizado hasta la fecha, por iniciativa municipal con la autorización de la Consejería de Cultura de la Junta de Andalucía, en el casco

28 En relación con el concejo de Algeciras establecido en la ciudad en 1344, véase: TorRemocha Silva, A., El Ordenamiento de Algeciras de 1345, Excmo. Ayuntamiento de Algeciras, Algeciras, 1983.

29 Véase nota 26. 
antiguo de la ciudad. Como la mayor parte de las citadas intervenciones se han efectuado en solares de lo que fue en el medievo la Villa Nueva o alBinya, edificada por los meriníes junto a la vieja medina andalusí entre 1279 y $1285^{30}$, el corpus de materiales y de datos que se ha logrado reunir se circunscribe casi exclusivamente al registro arqueológico crono-cultural meriní, con una breve secuencia de filiación castellana que lo amortiza (1344-1369). A pesar de esta circunstancia, los conocimientos aportados sobre la ciudad entre los años 1279 y 1369 han permitido configurar una realidad histórica que, hasta este momento, se había mostrado incompleta y ciertamente confusa ${ }^{31}$.

En lo que se refiere a la cultura material de filiación cristiana, que es la que interesa al contenido de este trabajo, es necesario decir que las secuencias estratigráficas presentan unos rasgos poco definidos, lo que confirma, por una parte la escasa incidencia de la repoblación cristiana ya reseñada, y por otra, la falta de originalidad de los materiales cerámicos de uso común de época castellana, período que, en lo que respecta a la cerámica destinada a preparación y cocción de alimentos, contenedores de fuego, higiene doméstica y personal y uso artesanal, debió representar una continuación de la producción cerámica anterior, producción que sería proporcionada

30 Véase: Torremocha Silva, A., Navarro Luengo, I. y Salado Escaño, J.B., Al-Binya, la ciudad palatina merini de Algeciras, Fundación Municipal de Cultura «José Luis Cano", Algeciras, 1999.

${ }^{31}$ A continuación se citan algunos de los trabajos publicados en los últimos años como resultado de las intervenciones arqueológicas realizadas en la ciudad entre 1995 y 1999: GENER BASALLOTE, J. M., "Aproximación a la evolución urbanística de la Villa Nueva de Algeciras desde la perspectiva histórico-arqueológica», en Caetaria, N. ${ }^{\circ}$ 1, Museo Municipal de Algeciras, Algeciras, 1996, pp. 53 a 66; del mismo autor, «Excavaciones arqueológicas de dos viviendas medievales islámicas en la Villa Nueva de Algeciras", en Caetaria, N.², Museo Municipal de Algeciras, Algeciras, 1998, pp. 87 a 98; TORREMOCHA SILVA, A., "La cerámica islámica estampillada del Museo Municipal de Algeciras", en Caetaria, N. ${ }^{\circ}$ 1, Museo Municipal de Algeciras, Algeciras, 1996, pp. 93 a 120; Torremocha Silva, A. y NavarRo Luengo, I., "La necrópolis meriní de Algeciras (sigios XIIIXIV). Una intervención arqueológicá de urgencia en la prolongación de la Avenida Blas Infante», en Caetaria, N. 2, Museo Municipal de Algeciras, Algeciras, 1998, pp. 99 a 130; TORREMOCHA SIEVA, A., Navario luengo, I. y Salado Escaño, J. B., "La Puerta de Gibraltar (Algeciras). Un ejemplo de ingreso adelantado de época meriní en al-Andalus», en Caetaria, N. ${ }^{\circ}$, Museo Municipal de Algeciras, Algeciras, 2000, pp. 187 a 208; MaRtínez EnAmorado, V., "Una inscripción califal de Algeciras», en Caetaria, N. ${ }^{\circ}$ 1, Museo Municipal de Algeciras, Algeciras, 1996, pp. 47 a 52 ; del mismo autor, "La maqabriyya almorávide dei Museo Municipal de Algeciras", en en Caetaria, N. 2, Museo Municipal de Algeciras, Algeciras, 1998, pp. 79 a 87; Martínez Enamorado, V. y Torremocha Silva, A., "Monedas de la Conquista. Algunos feluses hallados en la ciudad de Algeciras», en Caetaria, N. ${ }^{\circ}$ 3, Museo Municipal de Algeciras, Algeciras, 2000, pp. 135 a 150; Mora Serrano, B., «Hallazgos numismáticos en la necrópolis meriní de Algeciras», en Caetaria, N. ${ }^{\circ}$ 2, Museo Municipal de Algeciras, Algeciras, 1998, pp. 131 a 138 y NúÑEZ AgullaR, J. I., OSETE Lopez, M. L. y Bernal CaSASOla, D., «Estudio arqueomagnético de las murallas merinies de la Avenida Blas Infante, Algeciras (Cádiz)», en Caetaria, N. ${ }^{\circ} 3$, Museo Municipal de Algeciras, Algeciras, 2000, pp. 229 a 238. 
por los alfareros musulmanes que continuaron asentados en los entornos de la ciudad. No obstante, será en la cerámica de lujo, sobre todo en los formas destinadas a servicio y presentación de alimentos, donde se observe la sustitución de los tipos tradicionales islámicos (ataifores, jofainas, redomas, jarras y jarritas pintadas y esgrafiadas) por otros adaptados a la costumbre cristiana de alimentación individualizada (escudillas, cuencos, platos con borde en ala, copas, jarros y jarras, todos con cubierta vítrea estannífera sobre engalba blanca). Esta cerámica de estilo gótico-mudéjar, que llegará a Algeciras desde el Reino de Valencia (centros productores de Paterna y Manises), conforman en el registro arqueológico algecireño verdaderos «fósiles guía» que permiten la ajustada datación cronológica de los niveles cristianos exhumados, cuando otros testimonios materiales recuperados en dichos niveles no posibilitan una precisa datación de los mismos.

En el Museo de Algeciras se hallan depositados, procedentes de las intervenciones arqueológicas antes mencionadas, más de un centenar de fragmentos y piezas completas de cerámica gótico-mudéjar valenciana que, de acuerdo a los estudios realizados en yacimientos levantinos ${ }^{32}$, se han de datar dentro de un período cronológico que abarca desde 1345 hasta principios del siglo XV. En el caso de Algeciras, estos materiales de origen valenciano deben ser datados, por imperativo del proceso histórico local, entre 1344 y 1369 , lo que proporciona un hiato cronológico más restringido que el aportado por los yacimientos levantinos. La pertenencia de los materiales algecireños a lo que se ha considerado un «yacimiento cerrado", con unos precisos términos "post quem» y «ante quem", servirá sin duda para completar y ajustar los estudios realizados hasta el momento en la zona valenciana ${ }^{33}$.

De acuerdo a lo expuesto, es necesario poner en relación los abundantes testimonios cerámicos de procedencia valenciana hallados en Algeciras en

32 Véanse, entre otros, LERMA, J. V., et alii, «Sistematización de la loza gótico-mudéjar de Paterna-Manises», en III Congreso Internacional La Cerámica Medievale nel Mediterraneo Occidentale, Siena-Faenza, 1984, publicación de las actas en Firenze, 1986, pp. 183-203; LópEz Elum, P., «Origen y evolución de dos grandes centros cerámicos: Manises y Paterna", en el $/ / l$ Congreso Internacional La Cerámica Medievale nel Mediterraneo Occidentale, Siena- Faenza, 1984, publicación de las actas en Firenze, 1986, pp. 164-181; PAScUAL, J. y MARTí, J., La cerámica verdemanganeso bajomedieval valenciana, Serie Arqueología, $n .{ }^{\circ} 5$, Ayuntamiento de Valencia, Valencia, 1986; Martínez Caviro, B., La loza dorada, Madrid, 1982; Pinedo, C. y Vizcaino, E., La cerámica de Manises en la Historia, Edit. Everest, León, 1977 y LeRMA, J.V., Badía, A., López, I., MARimón, J. y Martínez, R., La loza gótico-mudéjar en la ciudad de Valencia, Monografías del Museo Nacional de Cerámica y de las Artes Suntuarias «González Martí», N.. 1, Ministerio de Cultura, Valencia, 1992.

33 Estos materiales cerámicos procedentes de centros productores valencianos bajomedievales se hallan actualmente en estudio por el Equipo de Investigación del Muso Municipal de Algeciras. 
niveles que amortizan los potentes registros de época meriní, con la existencia de la colonia de comerciantes catalano-aragoneses y del «Consulado de los Cathalanes", que tendrían en el abastecimiento de cerámica valenciana de Paterna y Manises destinada al servicio de mesa de los cristianos asentados en la ciudad, una de las más pujantes ramas de su comercio ${ }^{34}$.

Según la clasificación tipológica de Lerma et alli ${ }^{35}$, los ejemplares cerámicos exhumados en las intervenciones arqueológicas de Algeciras, hay que encuadrarlos, de acuerdo con sus características morfológicas y funcionales y el tipo de decoración que presentan, de la siguiente manera:

\section{a) Cerámica verde y morado}

Un alto porcentaje de las piezas recuperadas hasta el momento (aproximadamente el $50 \%$ ) se han de adscribir a las conocidas series decorativas con motivos ornamentales pintados bajo vedrío y realizados con óxido de cobre y manganeso sobre fondo de engalba blanca (Láms. 1 y 2). Hay representadas las siguientes series y tipos:

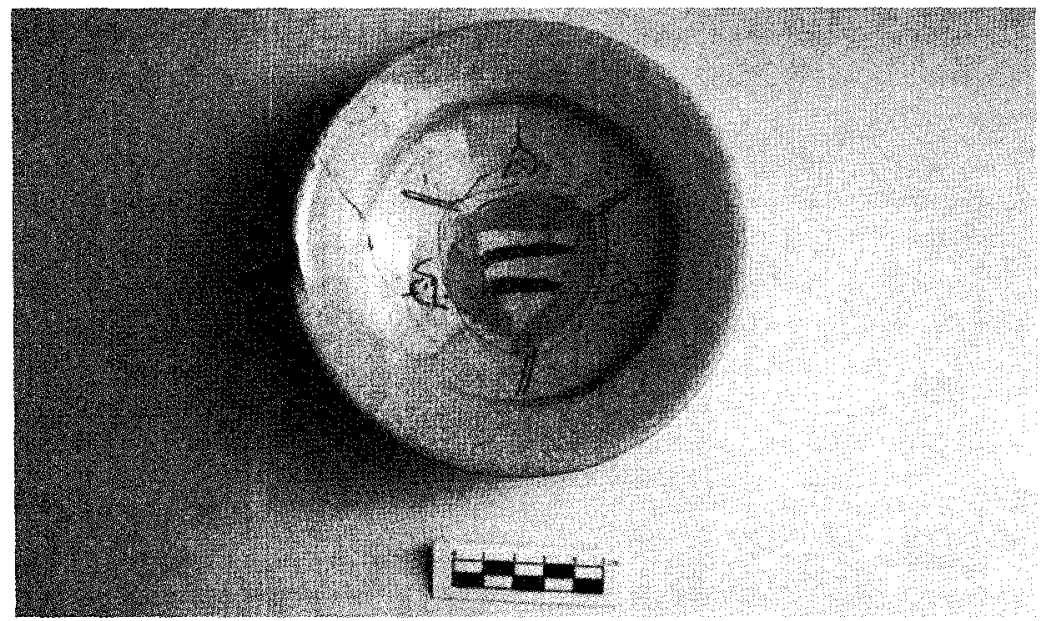

Lám. 1. Plato con borde en ala. Tipo de decoración "verde y morado». Serie «Paterna Evolucionado". (Museo Municipal de Algeciras, N. ${ }^{\circ}$ Inv. 1.824).

34 Estos tipos cerámicos, con una cronología de la segunda mitad del XIV y principios del XV, se han hallado también en los entornos de la Bahía de Cádiz. Una reciente intervención arqueológica de urgencia realizada conjuntamente por personal de los Museos de Algeciras y San Fernando en el Castillo de San Romualdo (San Fernando), ha proporcionado materiales cerámicos de Paterna decorados en verde y morado, azul y azul y dorado.

35 LERMA, J.V. et alii, op. cit., Valencia, 1992. 


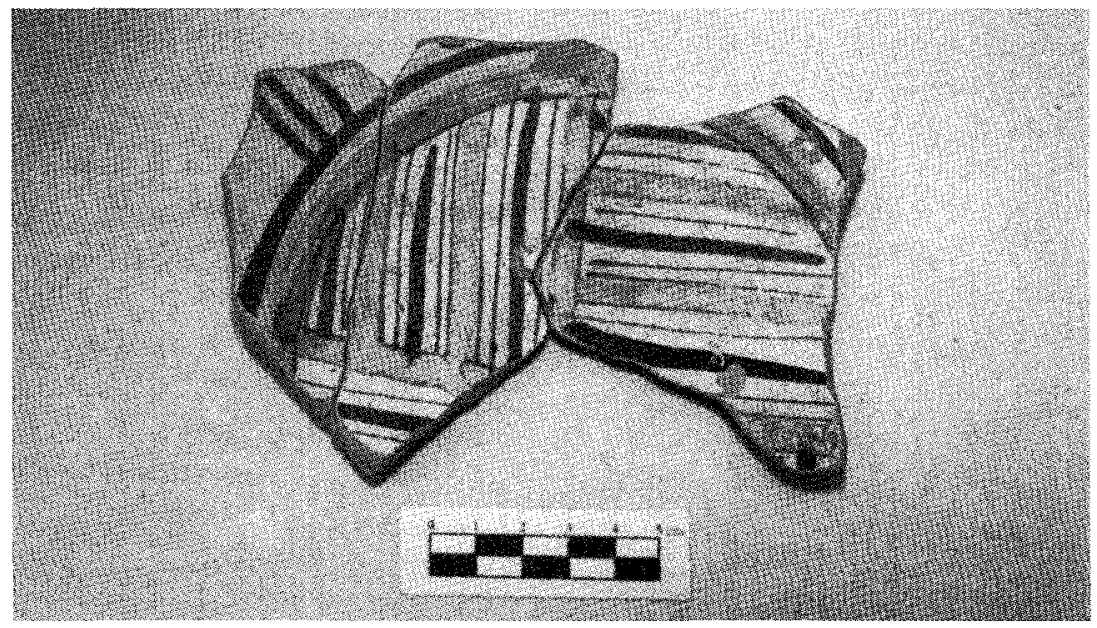

Lám. 2. Plato con borde en ala. Tipo de decoración «verde y morado». Serie «Paterna Evolucionado» (Museo Municipal de Algeciras, N. ${ }^{\circ}$ Inv. 900).

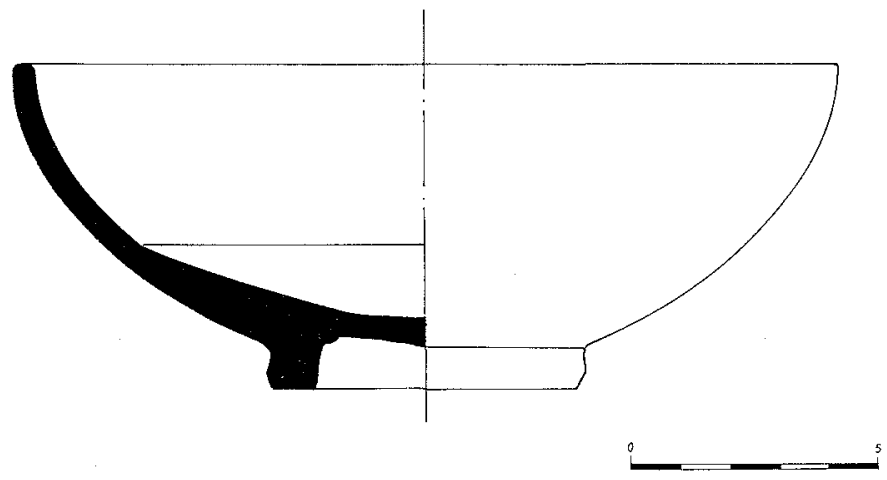

Fig. 3.a) Escudilla. Tipo de decoración "verde y morado». Serie «Paterna Evolucionado». Mediados del siglo XIV.

Grupo Plato, Familia A2, Tipo 1 b.

Grupo Escudilla, Familia A1, Tipo 1b (Fig. 3.a).

Grupo Tavach, Familia A1, Tipo 1b.

Grupo Jarro, Familia A, Tipo 1.

Grupo Grial, Familia D, Tipo 1 (sin decoración) (Lám. 3) y (Fig. 3.b). 


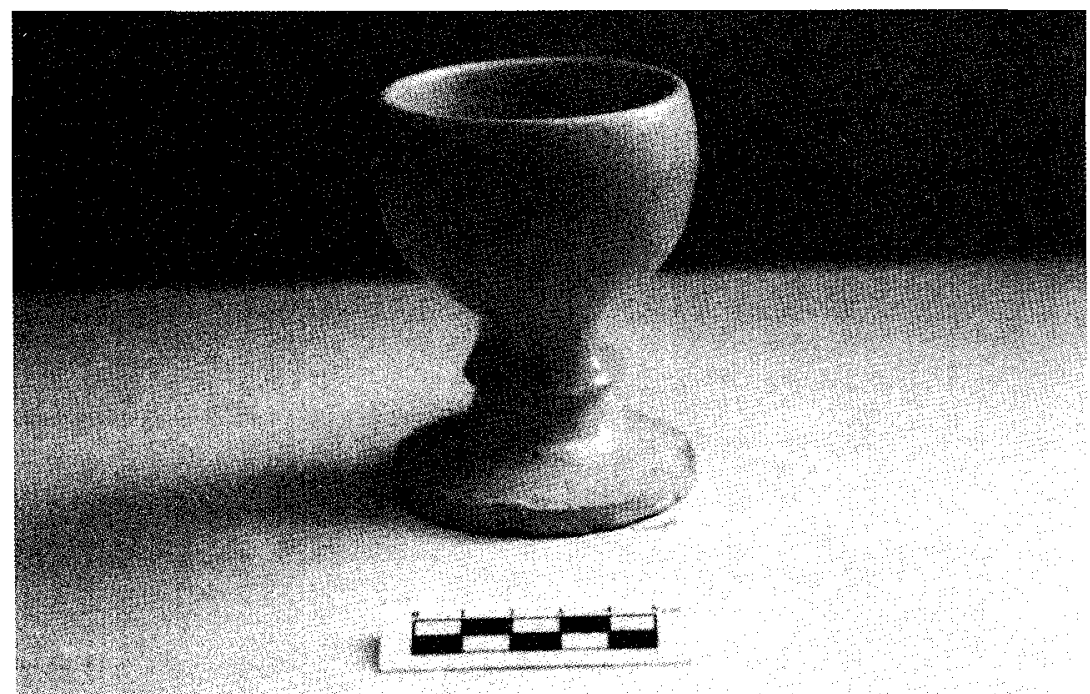

Lám. 3. Grial (Museo Municipal de Algeciras, N. ${ }^{\circ}$ Inv. 1.444).
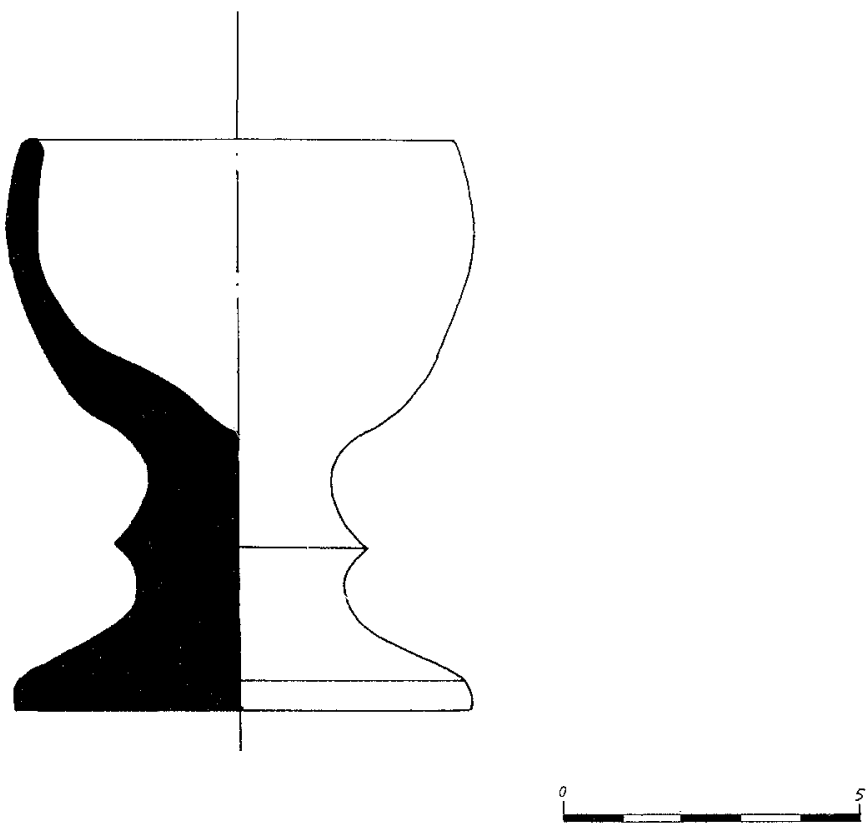

Fig. 3.b) Grial. Sin decoración. 
Relaciones comerciales entre la Corona de Aragón y Algeciras a mediados...

Si nos atenemos al modelo de los motivos decorativos representados, habría que agruparlos en la serie «Paterna Evolucionado», que se caracteriza por el dibujo poco cuidado y por una mayor separación de las cenefas con respecto al borde. Abundan los ejemplares con elementos heráldicos, con escudetes que contienen una, dos (Lám. 1 y Fig. 3.c) o tres bandas horizontales $u$ oblicuas. Su cronología habría que situarla en torno a mediados del siglo XIV. Otros ejemplares pertenecen a la serie denominada "Paterna Esquemático», más tardía y que se caracteriza por presentar diseños ornamentales sencillos, por los general simples trazos radiales. Son escasos los ejemplares que se encuadran en esta serie.

\section{B) Loza azul (Lám. 4)}

El número de hallazgos relacionados con este modelo es sensiblemente inferior al de verde y morado, existiendo la posibilidad, dada la similitud de

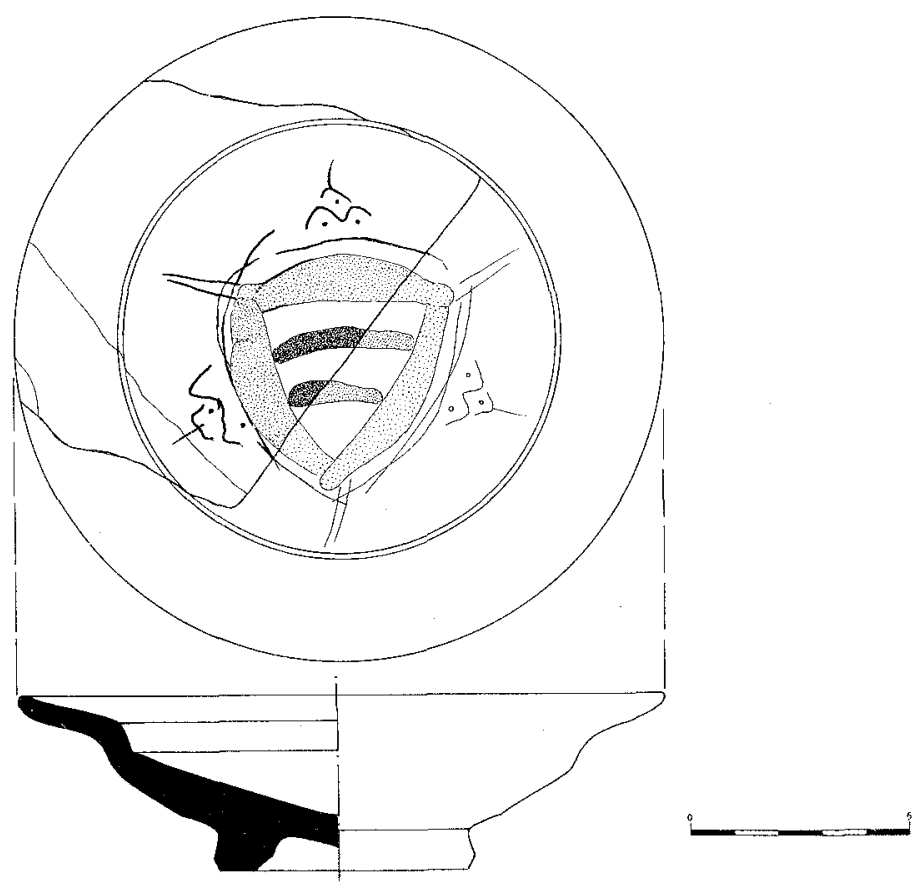

Fig. 3.c) Plato con borde en ala. Tipo de decoración "verde y morado». Serie «Paterna Evolucionado". Mediados del siglo XIV. 


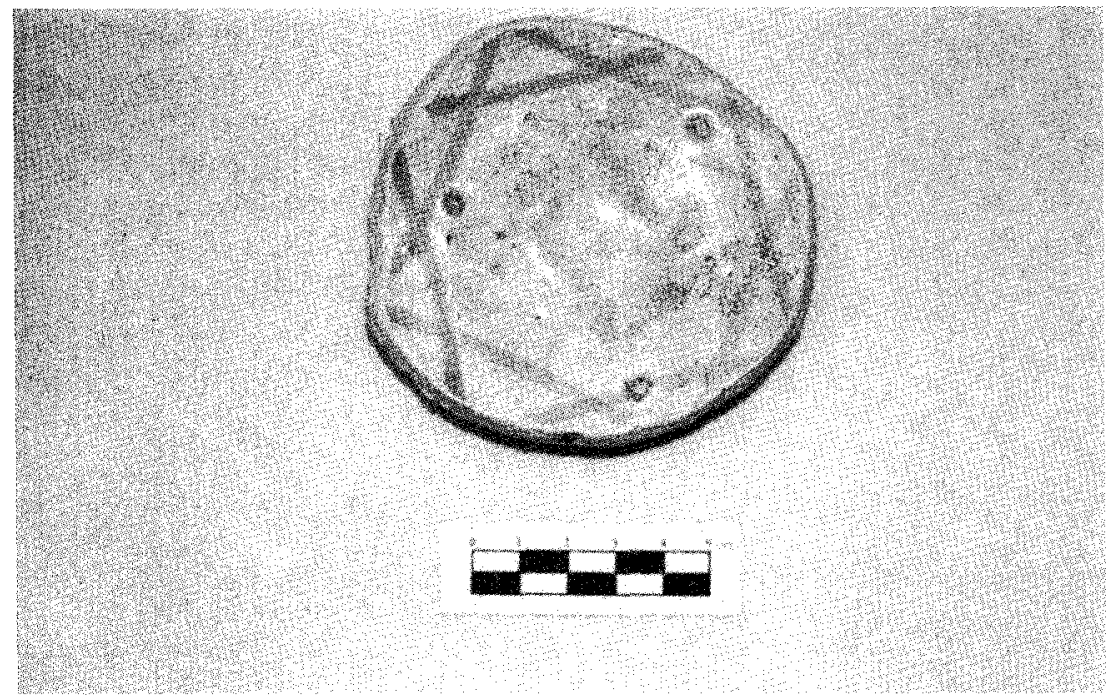

Lám. 4. Plato. Tipo de decoración «loza azul». Serie "Clásica». (Museo Municipal de Algeciras, $N .^{\circ}$ Inv. 1.542).

motivos decorativos y de formas, de que algunos ejemplares procedan del Reino Nazarí (alfares malagueños). La forma documentada en Algeciras se reduce, hasta el momento, a la denominada Grupo Escudilla, Familia A1, Tipo 1a y 1b de la clasificación de Lerma et alii.

En cuanto al tipo de decoración, hay que encuadrarla en la serie "Loza Azul Clásica», con un marco cronológico que abarca toda la segunda mitad del siglo XIV y primeras décadas del xv. También está representada la serie "Loza Azul Plena", que imita la "Loza Dorada Clásica», cuya cronología comparte.

\section{C) Loza dorada}

De los ejemplares que se han de adscribir a esta serie (aproximadamente un $15 \%$ del total de los ejemplares de loza gótico-mudéjar recuperados), la mayor parte hay que relacionarla con el Grupo Escudilla, Tipos I y II de Lerma et alii.

Los motivos decorativos, cuyas características fundamentales son: dorado de color cobrizo combinado con trazos de color azul claro y temática centrada, sobre todo, en motivos vegetales o geométricos, se han de 
adscribir al grupo denominado "Malagueño Evolucionado", que se produce durante la segunda mitad del siglo XIv (Lám. 5).

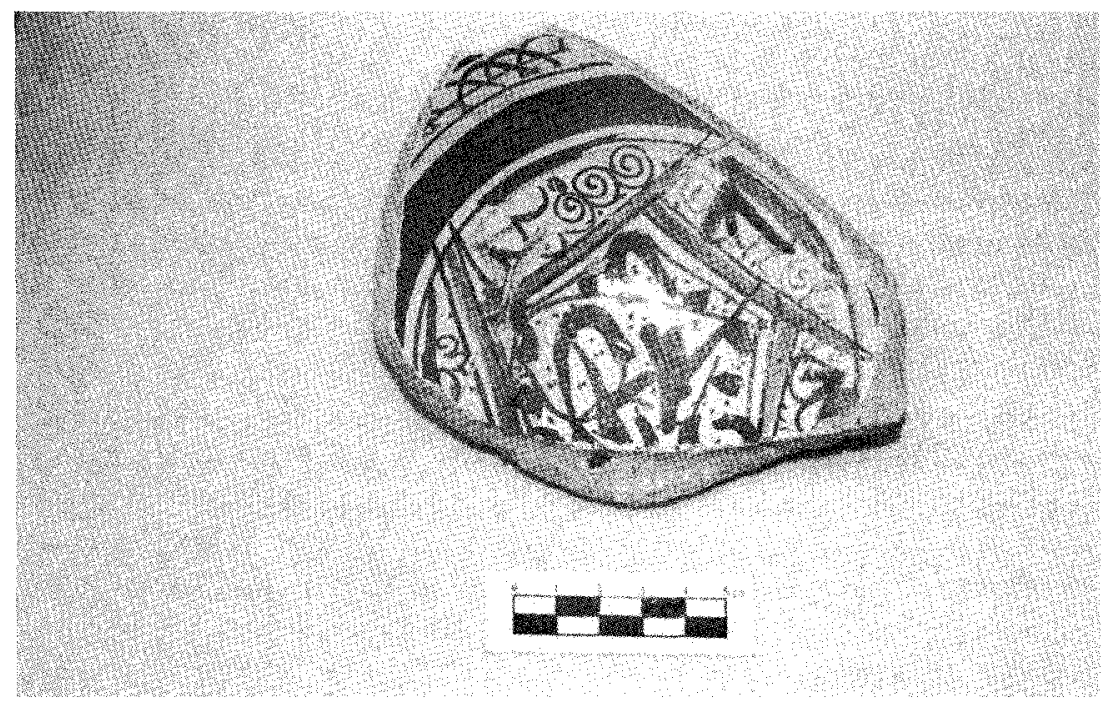

Lám. 5. Escudilla. Tipo de decoración «loza dorada». Serie «Estilo Malagueño Evolucionado" (Museo Municipal de Algeciras, N. ${ }^{\circ}$ Inv. 1.439).

\section{CONCLUSIONES}

Del análisis de la documentación presentada en este trabajo y del novedoso registro arqueológico aportado por las intervenciones realizadas en la ciudad entre 1995 y 1999 , se pueden extraer las siguientes conclusiones:

a) Presencia en la Algeciras cristiana (1344-1369) de una influyente colonia de mercaderes catalano-aragoneses establecida en torno al Consulado de los Catalanes documentado en la ciudad y activo, al menos, entre 1345 y 1359.

b) Existencia de intercambios comerciales entre Algeciras y la región valenciana desde 1344 hasta 1380, según demuestra la documentación conservada en el Archivo del Reino de Valencia. De ser cierta la segunda fecha, dichas relaciones comerciales habrían continuado durante la etapa nazarí de la ciudad (1269-1279). 
c) La recuperación de abundante cerámica gótico-mudéjar de origen valenciano (Paterna-Manises), con datación cierta entre 1345 y finales del siglo XIV, en los niveles que amortizan los estratos de época meriní, viene a confirmar la existencia y la intensidad de las citadas relaciones comerciales que tendrían en la distribución y venta de esta cerámica de lujo su principal ramo de comercio, desconociéndose el tipo de mercancias que los navíos cargaban en el viaje de retorno.

d) La presencia del Consulado Catalán y de la colonia de comerciantes catalano-aragoneses, así como la documentada existencia de una colonia de mercaderes genoveses asentada en torno a la "calle de Génova» de la ciudad, permite constatar la importancia que para las potencias comerciales mediterráneas que participaron en la toma de Algeciras -Aragón y Génova - tuvo esta ciudad, enclave portuario que, como sucede hoy, ejercía la función de puerto de escala entre los ámbitos mediterráneo y atlántico y de conexión entre ambas orillas del Estrecho.

\section{APÉNDICE DOCUMENTAL}

1356, marzo 14, Barcelona.

Carta del rey de Aragón, Pedro N, a los cónsules de los catalanes en Palermo, Mesina, Pisa, Catania, Túnez, Cartagena, Algeciras y otros lugares, en la que les comunica que, por causa de la guerra con los genoveses, antes de dos meses todos los bajeles que estuvieran en los dichos puertos que regresasen a puertos del Reino de Aragón.

(Archivo de la Corona de Aragón, Registro 1.402, fol. 38 v. ${ }^{\circ}$ ).

En Pere, etc... Al fael nostre lo consul deles Cathalans de Palerm, o son lochtinent, salut / e gracia. Significaram vos que nos per la guerra que havem ab los genovesos e altres enemichs nostres / e per ...... que nostres sotsmeses no prenguen danpnatge havem feta inhibicio general, que alos / navilis o vexells, grans o poch dela nostra senyoria no pusquen ne gosen partir de ports, pla-/-ges o maritimes de nostra senyoria, ni de lochs dela Reyna Darago muller nostra, ne de in-/-fants, ni de prelats, richs homes, ni daltres sotsmeses de la nostra senyoria deça ni della mar / sots pena de cors e daver sino en la forma enla dita inibicio contenguda prego notificats vos / la dita inibicio a vos dehim e manera que manets de part nostra a tots sotsmeses nostres nave-/-gants qui sien o seran en aquexes partides que dins spay de II meses apres quela present letre / los havrets notificada sien tornats en nostra senyoria ab lurs vexells per tenir e obser-/-var la dita inibicio en altra manera certificat los que sens tota mente serien encorreguts / en 
Relaciones comerciales entre la Corona de Aragón y Algeciras a mediados...

pena de cors e de aver. E ultra aque les signifiquets que nos havem dada licencia a tot / cosari e sotsmes nostre ques prengue de fer tots vexells, robes e mercaderies de nostres / sotsmeses que rroben enla mar contra la forma dela inibicio nostra damunt dita. Dada / en Barcelona, a XIIII dies de mars en layn de la Nativita de Nostre Senyor MCCCLVI./

(Simils infrascripts)

Al ffeel nostre lo consul deles Cathalans en Macina o a son lochtinent./

Al ffeel nostre lo consol deles Cathalans de Pisa./

Lo consol deles Cathalans de Cathania./

Lo consol deles Cathalans de Trapena o a son lochtinent./

Lo consol deles Cathalans de Napoles o son lochtinent./

Lo consol deles Cathalans Dalgezira, de Tenes, de Bugie, de Cartagenia, de Almaria, del Alger / de Sibilia, de Malica, de Bona, de Lione, del Loch, de Liora, de Alcudia, de Tedelis, de Mosta-/-gani, de Tuniz, de Septa, de Coyl. 